\title{
Prevalence of hypertension and its risk factors in southwest Ethiopia: a hospital-based cross-sectional survey
}

This article was published in the following Dove Press journal:

Integrated Blood Pressure Control

30 July 2013

Number of times this article has been viewed

Esayas Kebede Gudina'

Yadani Michael'

Sahilu Assegid ${ }^{2}$

'Department of Internal Medicine, Jimma University, Jimma, Ethiopia;

${ }^{2}$ Department of Epidemiology, Jimma University, Jimma, Ethiopia
Correspondence: Esayas Kebede Gudina Department of Internal Medicine, Jimma University, PO Box 5058, Jimma, Ethiopia Tel +25 I9। |7| 8500

$\mathrm{Fax}+25$ |47 III 8244

Email esakgd@gmail.com
Background: Hypertension is a common medical condition worldwide. It is an important public health challenge because of the associated morbidity, mortality, and the cost to the society. The objective of this study was to determine the prevalence of hypertension and its risk factors among attendants of adult outpatient departments at Jimma University Specialized Hospital in southwest Ethiopia.

Materials and methods: A hospital-based cross-sectional study was conducted on 734 participants aged 15 years or older from May 2012 to June 2012. A pretested structured questionnaire consisting of characteristics related to sociodemographic profiles and risk factors for hypertension was used for data collection. Three separate measurements of blood pressure and relevant anthropometric evaluation were taken according to current recommended standards. Chi-square test and other statistical analyses were done to employ appropriate interpretations of the findings. $P$-values of $<0.05$ were considered statistically significant.

Results: The mean age of the participants was $42.3 \pm 13.2$ years and $71.7 \%$ of them were 35 years and older; $58 \%$ of them were females. Overall prevalence of hypertension - defined by systolic blood pressure $\geq 140$ and/or diastolic blood pressure $\geq 90$ or reporting history of hypertension - was found to be $13.2 \%$. Only $35.1 \%$ of them were aware of their hypertension and only $23.7 \%$ were on treatment. The overall control rate was $15.5 \%$. Family history of hypertension, having diabetes mellitus, being overweight, and oral contraceptive use were associated with high blood pressure.

Conclusion: Hypertension was found to be prevalent; morbidity, awareness, treatment, and control in those with hypertension were low. Hence, intervention measures should be undertaken at the community level; particular emphasis should be placed on prevention by introducing lifestyle modifications and creating awareness about the problem so that early detection and intervention is possible.

Keywords: hypertension, cardiovascular disease, Ethiopia, Jimma

\section{Background}

There is no sharp demarcation between normal blood pressure (BP) and hypertension. However, for clinical purposes, hypertension is defined as systolic BP $(\mathrm{SBP}) \geq 140 \mathrm{mmHg}$ or diastolic BP (DBP) $\geq 90 \mathrm{mmHg}$, any prior diagnosis of hypertension made by a health professional, and taking antihypertensive drugs. ${ }^{1,2}$

Hypertension is an important public health problem accounting for about $6 \%$ of deaths worldwide. ${ }^{1}$ As much as 1 billion people have hypertension worldwide and 7.1 million deaths a year may be attributable to hypertension. ${ }^{2}$ High BP is responsible for $62 \%$ of cerebrovascular disease and $49 \%$ of ischemic heart disease. ${ }^{3}$ The prevalence of hypertension in general increases with advancing age, and it is higher in 
urban than rural areas due to differences in lifestyle..$^{4-7}$ In the Framingham Heart Study, ${ }^{5}$ the age-adjusted prevalence of hypertension was $18.5 \%$ in males and $28 \%$ in females.

Hypertension is asymptomatic and is usually diagnosed incidentally or after major organ damage has occurred. ${ }^{3}$ Independent risk factors for hypertension are obesity, high dietary salt intake, low dietary intake of calcium and potassium, alcohol consumption, psychosocial stress, low levels of physical activity, and family history of hypertension. ${ }^{1,2,8,9}$

Hypertension was thought to be rare in Africa, but it is now recognized as one of the most important cerebrovascular diseases contributing for about $40 \%$ of these diseases on the continent. $^{7,10-14}$ Its prevalence in urban areas is practically as high as that in the developed world, ranging from 5\% to $20 \%$ overall. ${ }^{8}$ Despite their growing importance in sub-Saharan Africa (SSA), hypertension and other cardiovascular diseases were not given due attention. An increasing burden of hypertension in this region will thus result in grave consequences, as only very few people get treatment, and control is likely to be low.

The epidemiology of hypertension in Ethiopia is not well studied. Some community-based surveys have shown that the prevalence of hypertension in the country varies from $1.8 \%$ in the rural community ${ }^{15}$ to $30 \%$ in urban areas of Addis Ababa and Gondar. ${ }^{16-18}$ Being obese or overweight, as well as physical inactivity, were strong predictors of hypertension in urban dwellers in Ethiopia. ${ }^{16}$

The main aim of this study was to assess the prevalence of hypertension and its risk factors among adults visiting outpatient units of Jimma University Specialized Hospital (JUSH) for various reasons. It will provide further information regarding the burden of hypertension and its risk factors to plan further interventions.

\section{Materials and methods Settings}

The study was conducted at JUSH, the only referral hospital in southwestern Ethiopia, with a catchment population of over 15 million. It is located in the town of Jimma, which is $356 \mathrm{~km}$ southwest of the capital, Addis Ababa. It is a general hospital with over 500 outpatient visits daily and 523 inpatient beds. Patients older than 14 years of age are treated at the adult wing of the hospital.

\section{Study design and period}

A cross-sectional study was conducted between May 2012 and June 2012 to determine the prevalence of hypertension and its risk factors among adults visiting outpatient units of the hospital for various ailments.

\section{Selection of participants}

All individuals aged 15 years or older attending the outpatient department for various reasons during the study period were recruited consecutively based on their willingness and eligibility to participate in the study.

\section{Exclusion criteria}

All patients with severe illnesses, acute life-threatening conditions, and severe injury, including patients with head injuries, were excluded from the study.

\section{Data collection}

A structured questionnaire that included variables on sociodemographic characteristics, risk factors for hypertension, and physical examination findings such as body weight, height, hip and waist circumferences, and three BP records was used for data collection.

\section{Consideration and procedures}

BP was measured using a mercury sphygmomanometer (adult size) and stethoscope. A patients' BP was taken while the patient was in a sitting position, from the right arm after the patient rested for at least 5 minutes before measurement. Three measurements of BP on a single visit were taken at least 3 minutes apart, and the averages of the three records were used for the computation of results. The point at which the first Korotkoff sound was heard was taken as SBP, and the DBP was taken to be the point at which the sound disappeared. ${ }^{8}$

Weight and height were measured with participants standing without shoes and wearing light clothing. Weight was measured using a digital weighing scale. The scale was calibrated to the zero level before each measurement, and was tested for repeatability of the measures. Height was measured by using a stadiometer while the patient was in an upright position.

Waist and hip circumferences were measured by using a flexible tape meter at both the level just above the iliac crest and at the maximum circumference of the hip, respectively.

\section{Data analysis and presentation}

The data were cleaned, edited, and entered into a computer to be analyzed using SPSS, Windows version 16.0 (IBM Corporation, Armonk, NY, USA). A chi-square test was used to analyze the associations between different variables, 
and other descriptive statistics were used where necessary. Multivariate and logistic regression analyses were done to see the association between dependent and independent variables. $P$-values of $<0.05$ were considered statistically significant.

\section{Data quality control}

Data collectors were trained for 1 day before the survey to ensure consistency and to reduce intra- and interobserver variations. Close supervision was done by the principal investigators throughout the data collection. Collected data were checked for completeness and consistency.

\section{Ethical consideration}

Ethical approval was obtained from the Jimma University Ethics Review Board. Written informed consent was obtained from participants after a comprehensive explanation of the purpose and procedure of the study in local languages. For participants younger than 18 years of age (and $\geq 15$ years of age), verbal agreement from the participants and written consent from attendants were obtained. The data collected from the participants will remain anonymous for an indefinite period of time. Patients incidentally found with lifethreatening conditions during the survey were referred to the emergency unit, and those with newly detected hypertension were advised to start follow-up treatment at the hospital or nearby health facility.

\section{Operational definition}

BP measurements of $\geq 140 \mathrm{mmHg}$ for SBP and/or $\geq 90 \mathrm{mmHg}$ for DBP were considered as elevated BP. Hypertension was defined as presence of persistently elevated BP or a history of treatment with antihypertensive agents.

Positive smoking history was based on patients' history of using manufactured or locally-made tobacco. Similarly, alcohol use was to refer to the consumption of local or manufactured alcohol beverages on a daily basis. Individuals who reported khat (Catha edulis leaves) use for 5 days or more in a week were considered to be regular khat chewers, and this was considered to be clinically significant.

Body mass index (BMI) $\geq 25$ but $<30 \mathrm{~kg} / \mathrm{m}^{2}$ was considered as overweight, and those above that range were considered obese. Abdominal obesity was defined as a waistto-hip ratio $(\mathrm{WHR})>0.85$ for women and $>1$ for men.

\section{Results}

\section{Background characteristics}

A total of 734 participants attending adult Out-Patients Department of JUSH were included in the study; $58 \%$ $(\mathrm{n}=426)$ of them were women. The age range was 15 years to 81 years, with a mean age of $42.3 \pm 13.25$ years. Nearly three-fourths $(71.7 \%)$ of the participants were 35 years or older. One-third of them (32.3\%) were farmers and $43.5 \%$ were illiterate (Table 1).

\section{Prevalence, awareness, treatment, and control of hypertension}

The overall prevalence of hypertension was defined as a systolic BP of $\geq 140 \mathrm{mmHg}$ and/or a diastolic BP of $\geq 90 \mathrm{mmHg}$; the percentage of those reporting a previous history of hypertension was found to be $13.2 \%$ (11.7\% in females and $15.3 \%$ in males, but there was no significant difference; $P=0.164)$. Most of the participants $(84.5 \%)$ had high $\mathrm{BP}$ at the time of the study $(\geq 140 / 90 \mathrm{mmHg})$; the rest were known hypertensive patients who had normal measurements at the time of this survey.

Table I Background characteristics of the adults visiting the Jimma University Hospital outpatient units, southwest Ethiopia, 2012

\begin{tabular}{|c|c|c|}
\hline & Number & $\%$ \\
\hline \multicolumn{3}{|l|}{ Age group in years } \\
\hline$<35$ & 208 & 28.3 \\
\hline $35-55$ & 423 & 57.6 \\
\hline$>55$ & 103 & 14 \\
\hline \multicolumn{3}{|l|}{ Gender } \\
\hline Male & 308 & 42.0 \\
\hline Female & 426 & 58.0 \\
\hline \multicolumn{3}{|l|}{ Marital status } \\
\hline Single & 147 & 20.0 \\
\hline Married & 537 & 73.2 \\
\hline Divorced & 8 & I.I \\
\hline Widowed & 42 & 5.7 \\
\hline \multicolumn{3}{|l|}{ Educational status } \\
\hline Illiterate & 319 & 43.5 \\
\hline Read and write & 21 & 2.9 \\
\hline Primary school & 41 & 5.6 \\
\hline High school & 136 & 18.4 \\
\hline Tertiary school & 217 & 29.6 \\
\hline \multicolumn{3}{|l|}{ Occupational status } \\
\hline Farmer & 237 & 32.3 \\
\hline Merchant & 36 & 4.9 \\
\hline Government employee & 173 & 23.05 \\
\hline Housewife & 251 & 34.19 \\
\hline Others & 37 & 5.04 \\
\hline \multicolumn{3}{|l|}{ Risk factors of hypertension } \\
\hline Family history of hypertension & 24 & 3.3 \\
\hline Diabetes mellitus & 16 & 2.2 \\
\hline Khat use & 539 & 73.4 \\
\hline Oral contraceptive use & 5 & 0.7 \\
\hline Coffee consumption & 513 & 69.9 \\
\hline Smoking & 99 & 13.5 \\
\hline
\end{tabular}


Only 19 of the 82 participants with high BP during this study (23.2\%) knew that they had hypertension. Among the 34 individuals who had a previous diagnosis of hypertension, only $23(67.6 \%)$ were being followed-up regularly and receiving drug treatment. However, only 15 (44.1\%) of previously known hypertensive patients had their BP controlled at the time of study. Putting these all together, the overall self-awareness of hypertension was $35.1 \%$, and the rates of hypertension treatment and hypertension control were $23.7 \%$ and $15.5 \%$, respectively (Table 3 ).

\section{Risk factors of hypertension Age}

An increasing prevalence of hypertension with age has been detected in this study. The mean age of those with hypertension was $45.8 \pm 10.2$ years, as compared to $41.8 \pm 13.5$ years for those with normal BP $(P<0.001)$. When categorizing by age, it was found that only $3.8 \%$ of adults younger than 35 years old were hypertensive. The prevalence rate of hypertension in those between the ages of 35 years to 55 years of age was $16.3 \%$, whereas $19.4 \%$ of adults older than 55 had hypertension $(P<0.001)$.

\section{Family history of hypertension}

Family history of hypertension was reported in 24 (3.3\%) of the participants, and in $19.6 \%$ of those with hypertension. It was found to be a strong risk factor of hypertension (odds ratio [OR]: 30.79; 95\% confidence interval [CI]: 11.18-84.78) (Table 2).

\section{Diabetes mellitus}

Sixteen (2.2\%) participants had been diagnosed with diabetes mellitus. The prevalence rate of hypertension in this group was found to be high $(37.5 \%$ in diabetic individuals versus $12.7 \%$ in nondiabetic individuals) (OR: 4.13 ; $95 \%$ CI: 1.47-11.65) (Table 2).

\section{Behavioral risk factors}

Certain behavioral risk factors for hypertension were assessed in the study. Over $73 \%$ ( $88.3 \%$ of men and $62.7 \%$ of women) of the participants reported khat use. However, its association with hypertension was only marginal with an OR of 0.627 (95\% CI: $0.4-1.0$ ).

About 13.5\% (99) of the participants reported having a history of cigarette smoking. Smoking prevalence was $31.5 \%$ in men and $0.5 \%$ in women. However, there was no significant association between smoking and hypertension $(P=0.052)$.
Table 2 Risk factors of hypertension among adults visiting the outpatient units of Jimma University Hospital, southwest Ethiopia, 2012

\begin{tabular}{|c|c|c|c|c|}
\hline & \multicolumn{2}{|c|}{ Hypertension } & \multirow[t]{2}{*}{ OR $(95 \% \mathrm{Cl})$} & \multirow[t]{2}{*}{$P$-value } \\
\hline & Yes & No & & \\
\hline \multicolumn{5}{|l|}{ Gender } \\
\hline Male & $47(15.3)$ & $26 \mid(84.7)$ & I.354 (0.882; 2.078) & 0.164 \\
\hline Female & $50(11.7)$ & $376(88.3)$ & & \\
\hline \multicolumn{5}{|c|}{ Family history of hypertension } \\
\hline Yes & $19(79.2)$ & $5(20.8)$ & 30.79 (II.18; 84.78) & $<0.001$ \\
\hline No & $78(11.0)$ & $632(89.0)$ & & \\
\hline \multicolumn{5}{|c|}{ Diabetes mellitus } \\
\hline Yes & $6(37.5)$ & $10(62.5)$ & $4.13(1.47 ; 11.65)$ & 0.004 \\
\hline No & $91(12.7)$ & $627(87.3)$ & & \\
\hline \multicolumn{5}{|c|}{$\mathrm{BMI}\left(\mathrm{kg} / \mathrm{m}^{2}\right)$} \\
\hline$\geq 25$ & $66(34.0)$ & $128(66.0)$ & $8.47(5.30 ; 13.53)$ & $<0.001$ \\
\hline$<25$ & $31(5.7)$ & $509(94.3)$ & & \\
\hline \multicolumn{5}{|c|}{ Drinking coffee } \\
\hline Yes & $56(10.9)$ & 457 (89.1) & $0.538(0.35 ; 0.83)$ & 0.005 \\
\hline No & $4 I(18.6)$ & $180(8 \mid .4)$ & & \\
\hline \multicolumn{5}{|l|}{ Khat use } \\
\hline Yes & 63 (1I.7) & $476(88.3)$ & $0.627(0.40 ; 0.99)$ & 0.042 \\
\hline No & $34(17.4)$ & $161(82.6)$ & & \\
\hline \multicolumn{5}{|l|}{ OCP use } \\
\hline Yes & $4(80.0)$ & I (20.0) & $32.6 \mathrm{I}(5.57 ; 298.02)$ & $<0.001$ \\
\hline No & $46(10.9)$ & $375(89.1)$ & & \\
\hline \multicolumn{5}{|l|}{ Smoking } \\
\hline Yes & $7(7.1)$ & $92(92.9)$ & $0.46 \mathrm{I}(0.2 \mathrm{I} ; \mathrm{I} .03)$ & 0.052 \\
\hline No & $90(14.2)$ & $545(85.8)$ & & \\
\hline
\end{tabular}

Abbreviations: $\mathrm{OR}$, odds ratio; $\mathrm{Cl}$, confidence interval; $\mathrm{BMl}$, body mass index; $\mathrm{OCP}$, oral contraceptive.

The prevalence of coffee drinking was $69.9 \%$. Hypertension was detected in only $10.8 \%$ of patients, as compared to $18.9 \%$ of those who never drank coffee (OR: 0.538; 95\% CI: 0.35-0.83) (Table 2).

\section{Oral contraceptive use}

Only five women reported ever using oral contraceptives, and four of them (80\%) were found to be hypertensive $(P<0.001)$.

\section{Body mass index (BMI)}

The mean BMI was $22.4 \pm 2.4 \mathrm{~kg} / \mathrm{m}^{2}$ (range: $13.2 \mathrm{~kg} / \mathrm{m}^{2}$ to $\left.41.3 \mathrm{~kg} / \mathrm{m}^{2}\right)$. About two-thirds of the participants $(65.9 \%)$ had a normal BMI, whereas $26.4 \%$ had a BMI $\geq 25 \mathrm{~kg} / \mathrm{m}^{2}$. Only one person had a BMI over $30 \mathrm{~kg} / \mathrm{m}^{2}$. BMI over $25 \mathrm{~kg} / \mathrm{m}^{2}$ was found to be a strong predictor of hypertension (OR: 8.47; 95\% CI: 5.30-13.53) (Table 2).

\section{Waist-to-hip ratio (WHR)}

The mean WHR was $0.92 \pm 0.11(1.01 \pm 0.12$ in men and $0.86 \pm 0.05$ in women). Overall, $14.7 \%$ of participants had 
a WHR exceeding 1, which was found in $33.1 \%$ of men as compared to $1.4 \%$ of women $(P<0.001)$. Applying separate definitions for abdominal obesity for women of WHR $>0.85$, $61.6 \%$ of them fulfilled the criteria. The prevalence of hypertension in men having a WHR of $>1$ was $41.2 \%$ versus $2.4 \%$ with a WHR of $\leq 1(P<0.001)$. Similarly, $14.2 \%$ of women with a WHR $>0.85$ had hypertension as compared to only $7.8 \%$ in those with a WHR of $\leq 0.85(P=0.045)$.

\section{Discussion}

This is a hospital-based cross-sectional study conducted in southwest Ethiopia. Hypertension was found to be prevalent. A large proportion of those with high BP did not know their hypertensive status before the study, and treatment and control rates in those with hypertension were very low. The findings from this study are helpful in strengthening the finding of previous studies conducted in the country, ${ }^{16,18}$ and will help alert policymakers so they can plan timely interventions.

The overall prevalence of hypertension was $13.2 \%$, which is significantly higher than that of previous reports in the country of $1.8 \%$ three decades ago. ${ }^{15}$ However, the current finding is lower than those found in most recent communitybased studies in Ethiopia (28.3\% in Gondar city, ${ }^{18}$ and 30\% in Addis $\mathrm{Ababa}^{16}$ ). This could be due to the fact that both of these previous studies involved urban dwellers only. In this study, $57 \%$ of the participants were from rural areas and $76 \%$ of hypertensive individuals were urban residents. This coincides well with findings in most studies conducted in SSA, where the prevalence rate of hypertension was found to be higher in urban dwellers than in rural dwellers. ${ }^{7}$ On the other hand, the two studies conducted in the country involved older individuals ( $\geq 25$ years in Tesfaye et a $^{16}$ and $\geq 34$ years in Awoke et al, ${ }^{18}$ as compared to $\geq 15$ years in our study). This has also undoubtedly resulted in this huge difference in the prevalence of hypertension.

When compared to the prevalence rates of hypertension in other parts of the world, the prevalence rate in southwestern Ethiopia is much lower than that of $28.6 \%$ in the USA, ${ }^{19}$ $44.2 \%$ in Europe,${ }^{20}$ and $44.8 \%$ in India. ${ }^{21}$ This finding is also lower than the prevalence rate of $21.8 \%$ for Uganda, ${ }^{22}$ and the estimated prevalence of $16.2 \%$ for $\operatorname{SSA}^{23}$ (Table 3 ).

An increase in the prevalence of hypertension associated with age has been detected in this study, which is consistent with the global trend. $2,7,16,18$ Women have lower prevalence rate of hypertension than men before menopause, but a higher prevalence thereafter. ${ }^{24}$ However, the overall prevalence rate is comparable among both

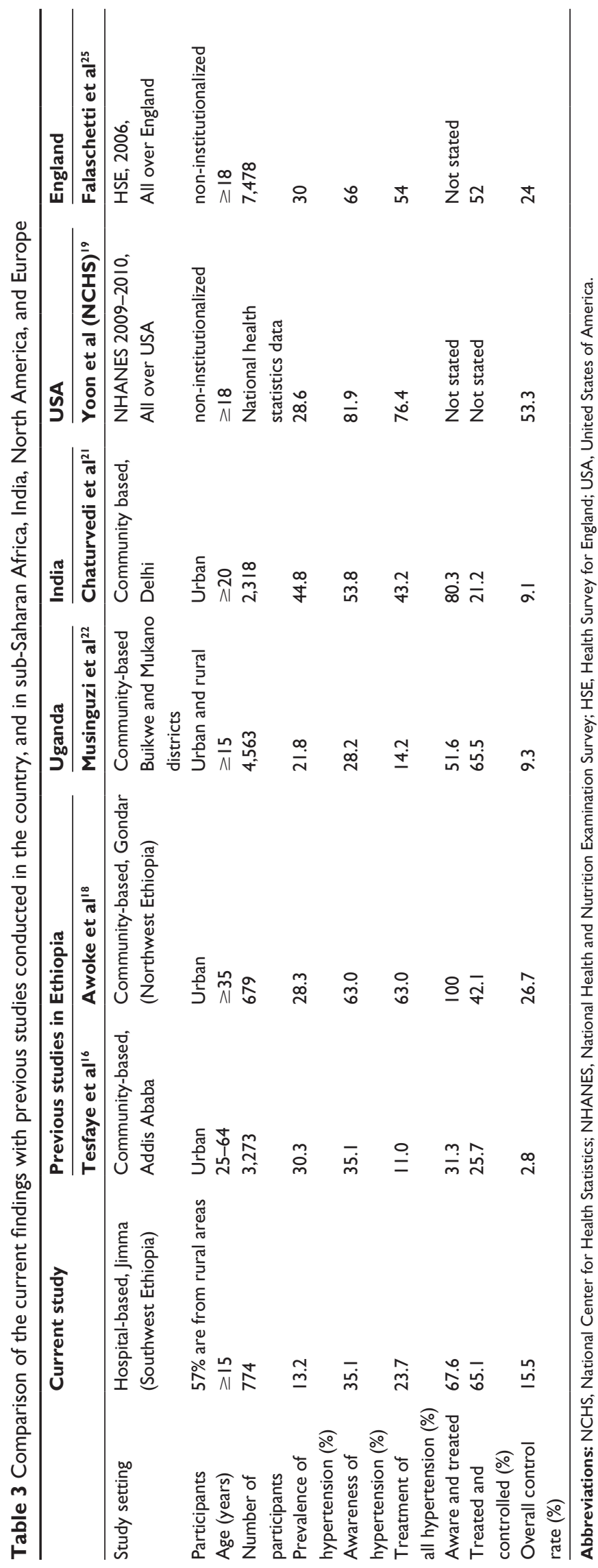


Table 4 Logistic regression analysis of the common risk factors for hypertension

\begin{tabular}{llll}
\hline Variables & $\begin{array}{l}\text { Adjusted } \\
\text { OR }\end{array}$ & $\begin{array}{l}\text { 95\% CI for } \\
\text { OR }\end{array}$ & P-value \\
\hline Age & I.053 & $(\mathrm{I} .02, \mathrm{I} .098)$ & $0.00 \mathrm{I}^{*}$ \\
Family history of hypertension & 23.885 & $(4.4 \mathrm{I}, 29.36)$ & $0.000^{*}$ \\
Coffee consumption & 0.504 & $(0.24, \mathrm{I} .07)$ & 0.073 \\
Khat use & 0.496 & $(0.24, \mathrm{I} .03)$ & $0.06 \mathrm{I}$ \\
Diabetes mellitus & $\mathrm{I} .009$ & $(0.1 \mathrm{I}, 9.68)$ & 0.994 \\
Oral contraceptive use & 50.758 & $(2.90,89.96)$ & $0.007^{*}$ \\
Body mass index $\left(\mathrm{kg} / \mathrm{m}^{2}\right)$ & $\mathrm{I} .509$ & $(\mathrm{I} .30, \mathrm{I} .76)$ & $0.000^{*}$ \\
High waist-to-hip ratio & $\mathrm{I} . \mathrm{I7I}$ & $(0.53,2.6 \mathrm{I})$ & 0.700 \\
\hline
\end{tabular}

Note: *Statistically significant at $P<0.05$.

Abbreviations: $\mathrm{OR}$, odds ratio; $\mathrm{Cl}$, confidence interval.

genders. ${ }^{24}$ Similarly, in this study and in previous studies conducted in the country, ${ }^{16,18}$ no significant difference in the prevalence of hypertension among both genders was detected.

Given the asymptomatic nature of hypertension, its detection is usually incidental, and at times only occurs after significant complications have arisen. ${ }^{3}$ As a result, the real burden of hypertension in most societies, particularly in the developing world, is underreported. ${ }^{6}$ Self-awareness, as well as the treatment and control of hypertension are very low in both low- ${ }^{16,18,21,22}$ and high-income countries, ${ }^{25}$ except in the $\mathrm{USA}^{24}$ where self-awareness, pharmacologic treatment, and control rates of hypertension are $81.9 \%, 76.4 \%$ and $53.3 \%$, respectively. In this study, of the 97 who were found to be hypertensive, only 34 (35.1\%) were aware of their hypertension and only $23(23.7 \%)$ were on pharmacologic treatment. The overall control rate was dismal at only $15.5 \%$ (Table 3 ). These factors might have contributed to the increasing burden of stroke ${ }^{26}$ and myocardial infarction ${ }^{27}$ in Ethiopia, where patients were diagnosed with hypertension only after these complications occurred.

Common risk factors for hypertension, such as a family history of hypertension, diabetes, or being overweight, have been found to be strongly associated with high BP in this study. Bivariate analysis for khat use, smoking, and coffee consumption showed some trends towards a lower prevalence of hypertension. However, when all possible risk factors were controlled using logistic regression analysis, their effects on hypertension vanished (Table 4). As participants were only asked about current use of these substances, which does not take into account their cumulative dose effects, an interaction between their use and risk of hypertension can hardly be established. The effect of their use on the risk of hypertension should be uncovered in a large-scale prospective study, or through analyzing the serum levels of potential active ingredients of these substances.

Using BMI criteria, only one person was classified as obese with a BMI exceeding $30 \mathrm{~kg} / \mathrm{m}^{2}$. However, the prevalence rate of abdominal obesity, which was defined as a WHR $>1$ for males and $>0.85$ for females, was strikingly high. Only, $13 \%$ of men in Tesfaye et al ${ }^{16}$ fulfilled the criteria for being obese; however, $33.1 \%$ of men in the current study had abdominal obesity. The figure for women is comparable between the two studies. ${ }^{16}$ The discrepancy between BMI and WHR in detecting obesity is an established fact. ${ }^{28,29}$ WHR is more sensitive in detecting cardiovascular risks than BMI. ${ }^{30}$ In this study, both high BMI $\left(\geq 25 \mathrm{~kg} / \mathrm{m}^{2}\right)$ and WHR $(>0.85$ for women and $>1.0$ for men) were associated with hypertension upon bivariate analysis. However, when controlling for other variables, only high BMI was associated with hypertension (Table 4).

Even though this survey has come up with important findings regarding the burden of hypertension in Ethiopia, there are certain limitations worth mentioning here. First of all, none of our patients knew their exact birth date, and as a result there was no reliable account of their age. Secondly, there was possibility that patients underreported their family history of hypertension and personal history of diabetes, which was based on only self-reports of a previous diagnosis. The fact that this was a hospital-based cross-sectional study indicates that this study may lack generalizability for the community at large. Finally, as this was a cross-sectional study, it is difficult to clearly state whether or not the behavioral risk factors preceded the occurrence of hypertension.

\section{Conclusion}

Hypertension was found to be prevalent in this population, but awareness, treatment, and control rates in those with the disease were low. Certain factors like family history of hypertension, diabetes, and being overweight were found to be associated with high BP. The findings in this study and other recent studies conducted in the country have clearly shown that hypertension is becoming a serious public health concern.

Thus, policymakers should make this chronic illness a part of the public health agenda, and they should plan timely interventions. Intervention measures at the community level should be undertaken using health education and other measures by providing an emphasis on the prevention, early detection, and treatment of hypertension. Furthermore, researchers and health care providers should work to uncover the burden of hypertension overall. 


\section{Acknowledgments}

The authors would like to kindly thank the study participants and Jimma University Hospital staff for making everything possible for this survey. We also thank Jimma University for funding the research.

EKG and YM designed the study, developed survey instrument, supervised data collection and data entry, and participated in data analysis and manuscript writing. SA participated in the study design, supervised instrument development, reviewed the analysis, and contributed to manuscript editing.

\section{Disclosure}

The authors report no conflicts of interest in this work.

\section{References}

1. Kotchen TA. Hypertension control: trends, approaches, and goals. Hypertension. 2007;49(1):19-20.

2. Chobanian AV, Bakris GL, Black HR, et al; National Heart, Lung, and Blood Institute Joint National Committee on Prevention, Detection, Evaluation, and Treatment of High Blood Pressure; National High Blood Pressure Education Program Coordinating Committee. The Seventh Report of the Joint National Committee on Prevention, Detection, Evaluation, and Treatment of High Blood Pressure: the JNC 7 report. JAMA. 2003;289(19):2560-2572.

3. World Health Organization. The World Health Report 2002: Reducing Risks, Promoting Healthy Life. Geneva, Switzerland: World Health Organization; 2002.

4. Kearney PM, Whelton M, Reynolds K, Muntner P, Whelton PK, He J. Global burden of hypertension: analysis of worldwide data. Lancet. 2005;365(9455):217-223.

5. Vasan RS, Beiser A, Seshadri S, et al. Residual lifetime risk for developing hypertension in middle-aged women and men: The Framingham Heart Study. JAMA. 2002;287(8):1003-1010.

6. Addo J, Smeeth L, Leon DA. Hypertension in sub-saharan Africa: a systematic review. Hypertension. 2007;50(6):1012-1018.

7. Opie LH, Seedat YK. Hypertension in sub-Saharan African populations. Circulation. 2005;112(23):3562-3568.

8. Hypertension control. Report of a WHO Expert Committee. World Health Organ Tech Rep Ser. 1996;862:1-83.

9. Pickering TG. The effects of environmental and lifestyle factors on blood pressure and the intermediary role of the sympathetic nervous system. J Hum Hypertens. 1997;11 Suppl 1:S9-S18.

10. Lekoubou A, Awah P, Fezeu L, Sobngwi E, Kengne AP. Hypertension, diabetes mellitus and task shifting in their management in sub-Saharan Africa. Int J Environ Res Public Health. 2010;7(2):353-363.

11. Whelton PK, He J, Muntner P. Prevalence, awareness, treatment and control of hypertension in North America, North Africa and Asia. J Hum Hypertens. 2004;18(8):545-551.
12. World Health Organization. The World Health Report 1998 - Life in the 21st Century: A Vision for All. Geneva, Switzerland: World Health Organization; 1998.

13. World Health Organization, Regional Office for Africa. Cardiovascular Diseases in the African Region: Current Situation and Perspectives: Report of the Regional Director. Maputo, Mozambique: World Health Organization, Regional Office for Africa; 2005.

14. Maiz HB, Kheder MA, Abderrahim E. Arterial hypertension in Tunisia. Saudi J Kidney Dis Transpl. 1999;10(3):372-375.

15. Zein ZA, Assefa M. Blood-pressure levels and hypertension in rural Ethiopian communities. Ethiop Med J. 1986;24(4):169-178.

16. Tesfaye F, Byass P, Wall S. Population based prevalence of high blood pressure among adults in Addis Ababa: uncovering a silent epidemic. BMC Cardiovasc Disord. 2009;9:39.

17. Lester FT. Blood pressure levels in Ethiopian outpatients. Ethiop Med J. 1973;11(2):145-154.

18. Awoke A, Awoke T, Alemu S, Megabiaw B. Prevalence and associated factors of hypertension among adults in Gondar, Northwest Ethiopia: a community based cross-sectional study. BMC Cardiovasc Disord. 2012;12:113.

19. Yoon SS, Burt V, Louis T, Carroll MD. Hypertension among adults in the United States, 2009-2010. NCHS Data Brief. 2012;107:1-8.

20. Wolf-Maier K, Cooper RS, Banegas JR, et al. Hypertension prevalence and blood pressure levels in 6 European countries, Canada, and the United States. JAMA. 2003;289(18):2363-2369.

21. Chaturvedi S, Pant M, Yadav G; Neelam. Hypertension in Delhi: prevalence, awareness, treatment and control. Trop Doct. 2007;37(3): $142-145$.

22. Musinguzi G, Nuwaha F. Prevalence, awareness and control of hypertension in Uganda. PLoS ONE. 2013;8(4):e62236.

23. Twagirumukiza M, De Bacquer D, Kips JG, de Backer G, Stichele RV, Van Bortel LM. Current and projected prevalence of arterial hypertension in sub-Saharan Africa by sex, age and habitat: an estimate from population studies. J Hypertens. 2011;29(7):1243-1252.

24. Igho Pemu P, Ofili E. Hypertension in women: part I. J Clin Hypertens (Greenwich). 2008;10(5):406-410.

25. Falaschetti E, Chaudhury M, Mindell J, Poulter N. Continued improvement in hypertension management in England: results from the Health Survey for England 2006. Hypertension. 2009;53(3):480-486.

26. Zenebe G, Alemayehu M, Asmera J. Characteristics and outcomes of stroke at Tikur Anbessa Teaching Hospital, Ethiopia. Ethiop Med J. 2005;43(4):251-259.

27. Mamo Y, Oli K. Trends of acute myocardial infarction admissions over a decade, Tikur Anbessa Hospital. Ethiop Med J. 2001;39(3):193-202.

28. Gandhi R, Dhotar H, Tsvetkov D, Mahomed NN. The relation between body mass index and waist-hip ratio in knee osteoarthritis. Can J Surg. 2010;53(3):151-154.

29. Jia WP, Lu JX, Xiang KS, Bao YQ, Lu HJ, Chen L. Prediction of abdominal visceral obesity from body mass index, waist circumference and waist-hip ratio in Chinese adults: receiver operating characteristic curves analysis. Biomed Environ Sci. 2003;16(3):206-211.

30. Asia Pacific Cohort Studies Collaboration. Central obesity and risk of cardiovascular disease in the Asia Pacific Region. Asia Pac J Clin Nutr. 2006;15(3):287-292.

Integrated Blood Pressure Control

\section{Publish your work in this journal}

Integrated Blood Pressure Control is an international, peer-reviewed open-access journal focusing on the integrated approach to managing hypertension and risk reduction. Treating the patient and comorbidities together with diet and lifestyle modification and optimizing healthcare resources through a multidisciplinary team approach constitute key

\section{Dovepress}

features of the journal. This journal is indexed on American Chemical Society's Chemical Abstracts Service (CAS). The manuscript management system is completely online and includes a very quick and fair peerreview system, which is all easy to use. Visit http://www.dovepress.com/ testimonials.php to read real quotes from published authors. 